https://www.amerabra.org; https://fspu.uitm.edu.my/cebs; https://www.emasemasresources.com/ $9^{\text {th }}$ Asian Conference on Environment-Behaviour Studies Perdana Kota Bharu, Kelantan, Malaysia, 28-29 Jul 2021

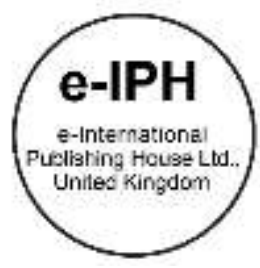

\title{
Current Usage of Standard Method of Measurement (SMM): Human behaviour issues
}

\author{
Anis Rosniza Nizam Akbar1, Siti Asmiza Muzafar2, \\ Mohammad Fadhil Mohammad ${ }^{1}$, Shariffah Zatil Hidayah Syed Jamaludin ${ }^{1}$ \\ ${ }^{1}$ Centre of Studies for Quantity Surveyors,Faculty of Architecture, Planning and Surveying, \\ Universiti Teknologi Mara (UiTM), Shah Alam, Malaysia \\ ${ }^{2}$ Civil Engineering Programme,Faculty of Engineering \& Built Environment, \\ Universiti Kebangsaan Malaysia,Bangi, Malaysia
}

anisrosniza@uitm.edu.my, asmizamuzafar@gmail.com,mfmohammad@uitm.edu.my,shariffah254@uitm.edu.my Tel of 1 st Author: +60199322447

\begin{abstract}
In response to the issues of generating an effective $B Q$ that is correctly measured, estimated, and quantified, there is a need for the industry's key players to be underpinned by a single standard method of measurement. Studies reported on the daunting issues of SMM usage, which affected generating an effective BQ. Through a survey and expert interviews, this study will attempt to disclose the behaviour usage of Malaysian SMMs in measuring Civil Engineering works. The results indicate that various SMMs still being used in developing BQs on the threshold of 2021.
\end{abstract}

Keywords: Bill of Quantity (BQ); Standard Method of Measurement (SMM); Human Behaviour; Usage of SMMs

eISSN: 2398-4287@ 2021. The Authors. Published for AMER ABRA cE-Bs by e-International Publishing House, Ltd., UK. This is an open access article under the CC BYNCND license (http://creativecommons.org/licenses/by-nc-nd/4.0/). Peer-review under responsibility of AMER (Association of Malaysian Environment-Behaviour Researchers), ABRA (Association of Behavioural Researchers on Asians/Africans/Arabians) and cE-Bs (Centre for Environment-Behaviour Studies), Faculty of Architecture, Planning \& Surveying, Universiti Teknologi MARA, Malaysia.

DOI: https://doi.org/10.21834/ebpj.v6i17.2873

\subsection{Introduction}

One of the significant sectors contributing to the growth of Malaysia's economic sector is the construction industry. There is an urgent need within the industry to implement standardization of construction information and documents to guarantee the development of the industry by providing a successful long-term, rational and cost-effective project or construction (Bandi \& Abdullah (2012); Hansen \& Salim (2015); Perumal \& Abu Bakar (2011). According to Abd Rashid (2002), the existence and nature of the construction industry operated through the separation and fragmentation of various organizations. Thus, information becomes an enabler and an essential contribution to coordination in order to minimize the effect of separation and fragmentation of various key players in the construction industry (Bandi \& Abdulllah (2012); Muse, Sullivan, \& Smith (2016)). Therefore, it is necessary to raise awareness of the significance of adopting standardization in construction information or data as an assurance of increasing construction efficiency. Standardization will thus indirectly reduce the conflict between the key players by helping to achieve consistency in management and operations. Perumal \& Abu Bakar (2011), supported by Muse, Sullivan, \& Smith (2016), emphasize that the main purpose of adopting standardization is to develop a specific level of conformity. In Malaysia, the Standard Method of Measurement (SMM) is a standard document localized to fit Malaysian local customs

eISSN: 2398-4287@ 2021. The Authors. Published for AMER ABRA cE-Bs by e-International Publishing House, Ltd., UK. This is an open access article under the CC BYNCND license (http://creativecommons.org/licenses/by-nc-nd/4.0/). Peer-review under responsibility of AMER (Association of Malaysian Environment-Behaviour Researchers), ABRA (Association of Behavioural Researchers on Asians/Africans/Arabians) and cE-Bs (Centre for Environment-Behaviour Studies), Faculty of Architecture, Planning \& Surveying, Universiti Teknologi MARA, Malaysia.

DOI: https://doi.org/10.21834/ebpj.v6i17.2873 
and practices. It also enables standardized measurements to produce a good $B Q$ used in a project as part of contract documentation (Mohammad (2012), Abd Rashid, Mustapa, \& Abd Wahid (2006); Adnan et al., (2011); Baccarini \& Peter (2002);

Hansen \& Salim (2015); Nizam Akbar et al. (2018a)). In other words, in producing a good BQ, SMM is needed. Additionally, there is an abundance of research conducted by Nizam Akbar et al. (2014a-2014c); Nizam Akbar et al., (2015); Nizam Akbar et al., (2018a); Nizam Akbar (2018b); Hansen \& Salim (2015); Muzafar (2021), indicating that when preparing a BQ, key players must be underpinned by a single standard document. The association between SMMs and BQs has been clarified in Figure 1, illustrating the importance of SMM towards a practitioner's roles and activities in both traditional and non-traditional procurement systems.

It shows unequivocally that the Quantity Surveyor (QS) use SMMs to standardize the process for producing measurements for building and civil engineering work when producing BQs as part of procurement or contract documentation. QS is representing clients, consultants and contractors. Abas et al. (2019) mention that it is a prerogative that civil engineers manage civil engineering contracts in Malaysia. Therefore, reacting to the statement, in some cases, the civil engineer will take over the roles of QS in preparing BQs for Civil Engineering Works. Nevertheless, the QS still need to recheck the BQs. As refers to a standard Memorandum of Agreement for professional quantity surveying services, preparing a $B Q$ is one of the core services provided by the $Q S$. The issue also being discussed by Oluwatosin \& Amos (2016) on the role of QS in managing civil engineering contracts. The involvement of QS at this stage is to verify that the BQ is prepared in accordance with the requirements outlined in SMMs so that contractors get accurate information (Muzafar (2021).

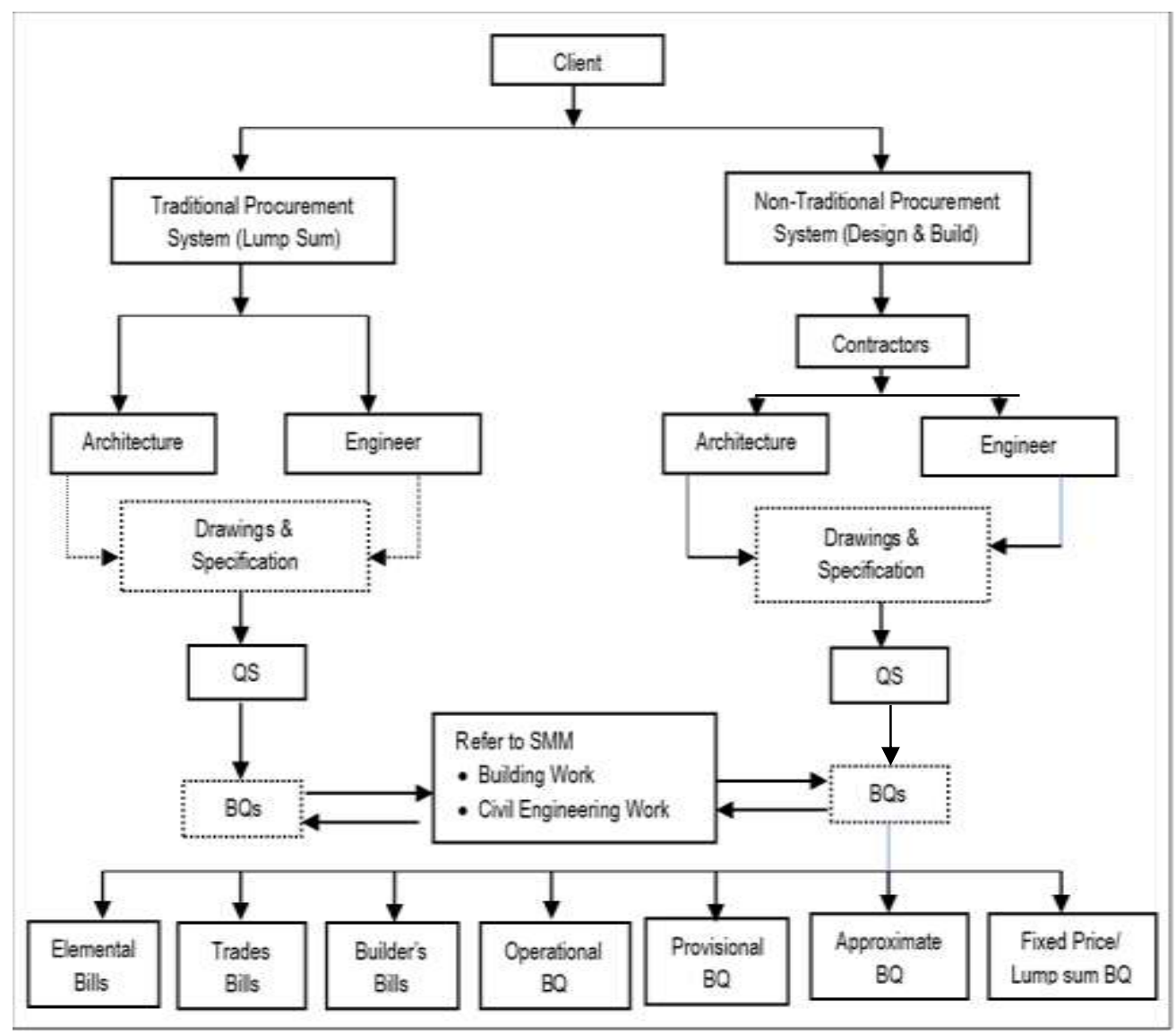

Fig. 1: Relevance and value of SMM in the key player roles and activities (Source: Nizam Akbar et al., 2015 and Nizam Akbar et al., 2018)

Meanwhile, in the perspective of Islamic, Abdul Rashid \& Hassan (2014a) touched on the existence of elements of gharar (uncertainty) in contracts documents, which is inconsistent with the maqasid al-shari'ah. Based on their study, the application of gharar elements seems insufficient to secure the interests of contracting parties. Abdul Rashid \& Hassan (2014a) indicate that Istisna is a Shariah-compliant tool in a contract where the subject matter does not exist. Abdul Rashid and Hassan (2014b) research discussed the validity of an Istisna' in the contract could achieve by knowing the nature, quality, quantity, and description of the asset to be manufactured known before entering into the contract. It seems that satisfying the stated condition can be fixed using BQs (Abdul Rashid and Hasan (2014b)). Therefore, to produce BQs that apply Istisna' requirements, a standard document is needed.

The discussion above portrays the importance of $B Q s$ underpinned on one standard document in preparing a $B Q$ that will form a part of the procurement or contract document. Although SMM is becoming more important in preparing BQs, there are still barriers to its use and adoption. Therefore, this study will attempt to investigate the current use of Malaysian SMMs for Civil engineering works in the Malaysian construction industry and determine its relation towards human behaviour in adopting Malaysian's current SMMs. 


\subsection{Background of the study}

According to the Construction Industry Development Board's (CIDB) statistics, the civil engineering sub-sector is the most significant contributor, accounting for RM63.7 billion in gross output (31.2\%). The record proves that civil engineering works are among the most significant contributors in supporting a country's economic growth. Industrial transformation is required to assist the country in speeding up the development of the construction industry and preparing for future financial needs. In this context, the Construction Industry Transformation Program (CITP) was created under the Fourth Strategic Thrust of Internationalization. The use of the Malaysian Civil Engineering Standard Measurement Method (MyCESMM2) was identified as one of the program's objectives. MyCESMMM2's objective is to encourage industry players to adopt the best practices in standardizing civil engineering works measurement. It is also designed according to the same standards to reduce confusion, enhance professionalism, interact with measurement methods, describe and define work coverage methods for each valued item. The CITP's implementation strategy was designed to utilize MyCESMM2 for all government projects by 2020. This study was designed and performed to determine how this standard measurement document was used in response to the strategy.

The following subchapter discussed the development of Malaysian Standard Method of Measurements' (SMMs) documentation for both sub-sectors; building and civil engineering. She then followed with a discussion on Malaysian's usage behaviour upon those documents and human behaviour issues that hinder the current Malaysian SMM usage.

\subsection{Development of Malaysia Standard Method of Measurement (SMM)}

Table 1 summarizes the developments of SMM during the last three (3) decades in Malaysia's construction industry. As referred to in Table 1, Malaysian is attempting to fulfil the need of the Malaysian construction industry by developing new SMMs for both buildings works and civil engineering works.

Table 1. Development of Malaysian SMMs

\begin{tabular}{|c|c|c|}
\hline & Name of SMM & Year of Publication \\
\hline \multirow{4}{*}{ 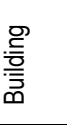 } & SMM First Edition (Imperial) & 1959 \\
\hline & SMM First Edition (Metric) & 1976 \\
\hline & SMM Second Edition (SMM2) & 2000 \\
\hline & MySMM2020 & 2020 \\
\hline \multirow{4}{*}{ : } & CESMM 3 from UK & 1991 \\
\hline & CESMM & 2003 \\
\hline & MyCESMM & 2011 \\
\hline & MyCESMM2 & 2018 \\
\hline
\end{tabular}

As shown in Table 1, the most recent SMM released for building works is MySMM2020, while MyCESMM2 is for SMM utilized in civil engineering. Nonetheless, there have been studies conducted by Malaysian researchers (Mohammad, 2012; Nizam Akbar et al., 2014a, 2014b; Nizam Akbar et al., 2015; Nizam Akbar et al., 2018a) that demonstrate the continued use of various kinds of SMMs by key players in the Malaysian construction industry. Surprisingly, the research also found that some respondents created their internal SMM when preparing $\mathrm{BQ}$.

Nizam Akbar (2018b) proposed a framework in remodelling the new Malaysian Standard Method of Measurement. However, the newly developed SMMs, MySMM2020 and MyCESMM2, may not relate to the frameworks since they are simultaneously created. As a result, this research is critical in reexamining the behaviours of QSs in the use of SMM in producing BQs as part of procurement and contract documents. It is necessary to conduct this study before the researchers review the latest Malaysian Standard Methods of Measurement documents', MySMM2020 and MyCESMM2.

\subsection{Malaysians' SMM usage behaviour}

As refer to the findings gain by Nizam Akbar et al. (2014a), a total of 25 face to face interviews were conducted among the selected key players from the clients, consultants and contractor's organization. The results of the study found that $75 \%$ of the consultants used SMM1 in measuring building works. Meanwhile, SMM2 is only fully used when dealing with government projects. For civil engineering work, either CESMM3 (UK) and CESMM Malaysia are used, and some refer to SMM2 or self-designed measurement methods when preparing BQ for civil engineering work. The study also discloses a critical issue, whereby $58 \%$ of the respondents said they did not know about the existence of the newly launched document (MyCESMM, 2011), even though the study was conducted in 2014, three (3) years after the document launched. The concerns raised above emphasize the need of researching the use of SMMs in the Malaysian construction industry.

Additionally, in light of the newly developed SMMs for Malaysia; MySMM2020 (launched in 2020) and MyCESMM2 (launched in 2018 ), a study examining the use of both newly developed SMMs among key players in our industry is necessary to validate the statutory and regulating body's effort in developing those documents. In light of the concerns raised, this study investigated the behaviour usage of SMMs implemented in the Malaysian construction industry.

According to Muzafar (2021), Nizam Akbar (2018), Hansen \& Salim (2015), Ganiyu \& Mohamed (2012), human behaviour is one of the barrier factors that hinder the use of the standard method of measurement. The issues are divided into two categories; directly related to human behaviour and the statutory and regulating bodies actions. The issues that are related to human behaviour are i) unaware on the benefit of SMM, ii) unwilling to shift from their existing practices, iii) lack of measurement skill and iv) need more extended time in the adaption of new SMMs. Meanwhile, issues related to the statutory and regulating bodies actions are i) lack of regulatory bodies for standard enforcement, ii) lack of promotion from governing body, iii) lack of training and iv) lack of incentive. Based on the literature review, barrier 
factors can potentially affect industry players' acceptance of using the most current SMM in the Malaysian Construction industry (Muzafar 2021).

\subsection{Methodology}

In order to achieve the aim of this paper, the primary data was gathered through a questionnaire survey and supported with expert interview sessions. Due to the pandemic issue, both methods are conducted online. The professionals targeted for the questionnaire survey are mainly QSs working in a QS consultant firm only. The purpose of setting the limits of the respondents among the consultant QS is to explore the usage of SMMs for Civil engineering works implemented in the Malaysian construction industry. The organization that used SMM in preparing $B Q$ are among consultants only. The respondents should also directly deal with preparing civil engineering $B Q s$. The researchers have used a random sampling method since the scope of the population is only focused on QS who registered with BQSM under the Selangor region only. Selangor was selected because the state was one of the most significant contributors to the construction industry (refer to Construction Statistics, Quarterly Second Quarter 2020). Furthermore, Selangor recorded the highest number of QS firms registered with the Board of Quantity Surveyors (BQSM) and the Ministry of Finance Malaysia, 30\% compared to other states. Regarding the table of Krejcie \& Morgan (1970), if the population is 415 , the study's accepted sample size would be 200 . Therefore, 200 questionnaires were distributed. The process of distributing and collecting the questionnaires is within five months, from March to August 2020. At the end of August 2020, only 75 feedbacks from the respondents were received.

Table 2. Number of populations, allowable sample size and its response rate

\begin{tabular}{cccc}
\hline Population & Sample size & Respond rate & $\%$ of response rate \\
\hline 416 & 200 & 75 & $37.5 \%$ \\
\hline
\end{tabular}

Responses for the study have exceeded the norm for questionnaire surveys that were set up globally $(15-20 \%)$ and within the Malaysian construction industry (14\%-30\%), respectively (Nizam Akbar 2018b). Thus, the total response rate of $37.5 \%$ reported in Table 2 is well within the standard set-up and subsequently deemed reasonable. The value of mean and mode are used in exploring the issues that hinder the usage of current Malaysian SMMs. The researcher has performed an expert interview with six (6) experts from academia and industry with over ten (10) years of working experience to support figures gain on the issues that hinder the total usage of Malaysian SMMs for Civil engineering works. The interview participants being distributed with the same set of questionnaire survey questions to be answered. During the interview's session, the questions being prolonged in a calculating manner to ensure a solid answer that reflected the status of these experts. In the context of this research, expert panels have been defined as i) a professional experienced in the use and interpretation of SMM, ii) a person who is measuring construction works based on existing standards for at least two (2) years; iii) a person previously involved in drafting the SMM and iv) a person who is teaching measurement-related subjects, which involves the interpretation of SMM in higher institutions of learning.

\subsection{Results and Discussion}

As summarized in Table 3, the result showed the detailed distribution of the respondents. It indicates female respondents were nearly equal to male respondents, 37 and 38 numbers respectively. The majority of the respondents are 25 to 50 years in the age distribution context, with $74.7 \%$. Regarding the distribution of experience in construction, $42.7 \%$ of the respondents have fewer than five years. Meanwhile, more than half (54.7\%) got a medium range of experience (5-30 years). In order to ensure the data collected are reliable, the respondents have been asked to indicate their involvement in preparing BQs. The figure indicates that respondents are acquainted with producing $\mathrm{BQs}$ and possess the necessary information to complete the questionnaire, resulting in more accurate analysis.

Table 3. Respondent Profile

\begin{tabular}{lll}
\hline & Frequency & Percentage (\%) \\
\hline Gender & & \\
Male & 37 & $49.3 \%$ \\
Female & 38 & $50.6 \%$ \\
\hline Age & & \\
$<25$ & 15 & $20 \%$ \\
$25-50$ & 56 & $74.7 \%$ \\
$>50$ & 4 & $5.3 \%$ \\
\hline Experience & & \\
$<5$ & 32 & $42.7 \%$ \\
$5-30$ & 41 & $54.7 \%$ \\
$>30$ & 2 & $2.6 \%$ \\
\hline Position & & \\
Director & 3 & $4 \%$ \\
Senior QS & 14 & $18.7 \%$ \\
QS & 40 & $53.3 \%$ \\
Assistant QS & 18 & $24 \%$ \\
\hline Involvement in preparing BQ & & \\
Yes & 75 & $100 \%$ \\
No & 0 & $0 \%$ \\
\hline
\end{tabular}


As potted in Fig 2, the result showed the frequency of SMMs' usage by the respondents in preparing civil engineering works' $B Q$. Surprising more than half $(65 \%)$ of the respondents openly claimed that they are still using SMM2 in preparing BQ for civil engineering works. Twenty per cent (20\%) of the respondents are still using MyCESMM in preparing civil engineering works, and another one per cent $(1 \%)$ of the respondent referring to other documents (in-house standard Method of Measurement) in preparing Civil Engineering Works' BQ. Only fifteen per cent (15\%) of the respondents refer to the most current SMM for civil engineering; MyCESMM2. The findings were again repeating the behaviour of the Malaysian construction industry by referring to outdated SMMs in producing BQs, as reported in Nizam Akbar et al. (2014a). Although the scenario percentage reduced approximately ten per cent (10\%) (from $75 \%$ to $65 \%$ ) for SMM2 usage, this scenario remains frightening and continues to become a source of academic and industry concern. It is due to the usage percentage of the most current Malaysian SMM for Civil Engineering Works is still low (14\%). The results shown in Fig. 2 portrays the issues whereby although the importance of being underpinned by one standard document in preparing BQs has increased recently, barriers to its application and adoption still exist.

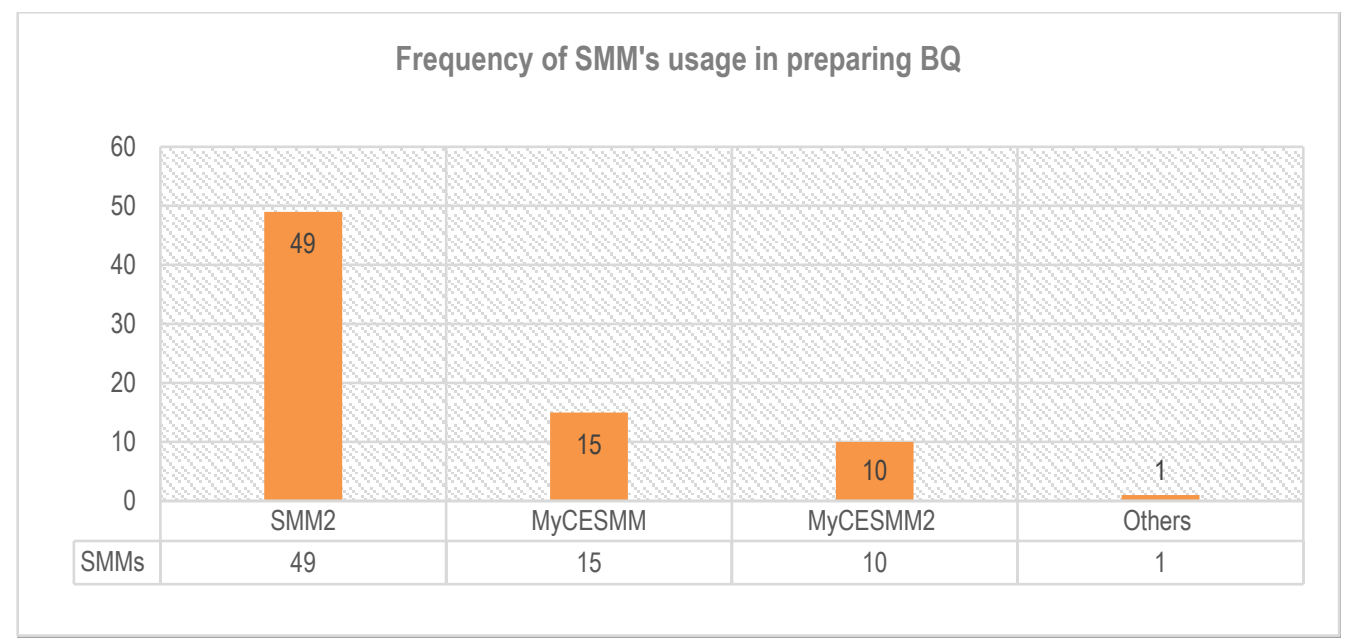

Fig 2: Frequency of SMMs' usage in preparing Civil Engineering Works' BQs

Table 4 illustrated the mean and mode value from the respondents and interview participants on the issues identified that hinder the usage of current Malaysian SMMs for Civil Engineering Works. Table 4 disclosed seven (7) issues with a big difference in the mean value and rank. Only one issue seems to get the same rank; the fourth rank with different mean values, 3.88 and 3.34 , respectively. The issue that ranked as the fourth issue that most hinder the usage of current Malaysian SMMs is; unwilling to shift from their existing practices.

Table 4: Mean and mode value on the issues identified hinder the usage of current Malaysian SMM for Civil Engineering Works

\begin{tabular}{|c|c|c|c|c|c|c|}
\hline & \multicolumn{3}{|c|}{ Respondents } & \multicolumn{3}{|c|}{ Expert Panel Interview } \\
\hline Issues hinders the usage of the current Malaysian SMMs & Mean & Mode & Rank & Mean & Mode & Rank \\
\hline Unaware on the benefit of SMM & 3.95 & 4.00 & 1 & 2.86 & 3.00 & 8 \\
\hline Unwilling to shift from their existing practices & 3.88 & 4.00 & 4 & 3.34 & 4.00 & 4 \\
\hline Lack of measurement skill & 3.94 & 4.00 & 2 & 3.40 & 4.00 & 3 \\
\hline More extended time in the adaption of new SMMs & 3.72 & 4.00 & 6 & 3.12 & 3.00 & 7 \\
\hline lack of regulatory bodies for standard enforcement & 3.76 & 4.00 & 5 & 3.74 & 4.00 & 1 \\
\hline Lack of promotion from the governing body & 3.71 & 4.00 & 7 & 3.29 & 4.00 & 5 \\
\hline Lack of training & 3.93 & 4.00 & 3 & 3.24 & 4.00 & 6 \\
\hline Lack of incentive & 3.69 & 4.00 & 8 & 3.70 & 4.00 & 2 \\
\hline
\end{tabular}

The first issues rank by the respondents that hinder the usage of the most current Malaysian SMMs for Civil Engineering Works is the occurrence of unawareness on the benefit of SMMs among the consultant and clients. They were unaware of the beneficial impact of a reliable SMM in delivering good BQs on overall contract management monitoring and pricing. The experts claimed this behaviour as the last factor that could hinder the usage of the most current Malaysian SMMs. The experts denied this factor to become the first factor because the lack of regulatory bodies for standard enforcement is more critical for them. The experts asserted that if no regulatory authorities enforce standards and the organization gains no benefit, the old practice will continue as long as the project's stakeholders communicate well. The problem's consequence is that inconsistency in the use of standard measurement techniques will persist. Experts also argue that the construction industry will be aware of the existence and benefits of new developed SMMs when the government gazetted or mandates that SMMs. The second issue ranked by the respondents is the lack of measurement skills among the end-user. Meanwhile, for experts, this issue is ranked as the third issue. The practitioner needs to equip themselves with high measurement skills by exposing them to various civil engineering construction methods. The second critical issue highlighted by the experts is to encourage the practitioners to fully adopting current SMMs is the lack of incentive. The experts suggested that the contractor will not refuse to adopt standard measurement methods if Incentives are provided to the contractor.

The approach claimed to be as per Maslow principle by looking at the increment of Industrialized System (IBS) consumption in Malaysia, where IBS projects will receive incentives from the government. The latest is on the application of Building Information Modelling (BIM) in the Industrial Revolution era (IR 4.0). 
As per Table 4, lack of promotion is the fifth rank, ranked by the experts. Meanwhile, the respondents ranked it as the seventh rank. The experts claimed that the current method and approach used by the governing body in promoting new developed SMMs is not enough. They are not promoted proactively, especially toward the practitioners. The experts do not question the governing body's efforts to promote such documents among academia but are more concerned with the promotion components among practitioners. Billboard and continuously promotion through official website are the platforms suggested by the experts. Dissemination of information, promotion of and enhancement awareness of the practitioners suggested openly conducted through workshops, seminars, and conferences.

The next rank ranked by the experts is lack of training. The experts stressed that to encourage practitioner adoption of current Malaysian SMMs, training needs to be expanded and introduced in every continuous professional development (CPD) program of the Malaysian Board of Quantity Surveyors and the Malaysian Institute of Engineers. More extended time in the adaption of new SMMs is the second last factor ranked by the experts. In other words, the end-user needs more time for them to fully adopting new SMMs. The experts claimed that this behaviour might be due to the low learning curve among the practices because of their age (for the senior practitioner) and lack of measurement skills among new staff.

The mean value for each issue identified is mainly between 3.12 to 3.95 , except for expert panel interview mean value for unaware on the benefit of SMM with 2.86 mean value and 3.00 mode value. Again, all listed factors above are supported through Nizam Akbar et al. (2014-2018). The discussion above concluded that, although the governing body produces the most current SMMs, the end-user still does not fully utilize the documents. It is because innate human behaviour is unwilling to change and takes a long time to change when they are not getting physical or material-intensive.

\subsection{Conclusion and recommendation}

In order to resolve the issues, mandatory the document is one of the solutions to be applied, followed by development and research activities to strengthen the standard documents. The development and research activities need to be regularly carried out based on industry players' views and international best practice benchmarking processes. Besides that, incentives need to be introduced to encourage and motivate industry players to use that document. In addition to that, briefing, training sessions, and proactive and efficient promotional activities need to be carried out to increase awareness of the current Malaysian SMM.

The findings of this paper serve as a starting point for refreshing and illustrating the real-world challenges confronting Malaysian SMMs before planning the next action course. The findings demonstrated the presence of out-of-date SMMs still being used in producing a critical document, $B Q$ s, that will form a part of the procurement or contract that binds parties in the construction industry. The findings significantly add to the relevance and deservingness of this study before the researchers proceed further on the issues related to the most current Malaysian Standard Method of Measurements documents which are MySMM2020 and MyCESMM2.

\section{Acknowledgements}

The authors would like to extend the utmost appreciation to University Technology MARA (UiTM), Shah Alam and Universiti Kebangsaan Malaysia, Bangi, for the continuity and success of this research.

\section{Paper Contribution to Related Field of Study}

This paper discloses the behaviour usage of the most current Malaysian SMMs. Developing an acceptable standard document is a big challenge coupled with human behaviour that is difficult to go through changes adds a burden to the statutory and regulating bodies.

\section{References}

Abas A.A., Ismail, F., Ismail, Z. (2019). Reliable Description of Preliminaries Item Using Civil Engineering Preliminaries Protocol (CEPP) In Conventional Contracts. Journal of Building Performance ISSN, 10 (2), https://doi.org/10.1051/matecconf/201926603006

Abd Rashid, K. (2002). Construction Procurement in Malaysia: Processes and Systems: Constraints and Strategies. Kuala Lumpur: Research Centre International Islamic University Malaysia.

Abdul Rashid, K., Hasan, S.F. (2014a). Proposed Istisna' Model for Construction Works Contracts. The 2nd Kyoto University-IIUM Research Colloquium Shari'ah Compliance Issues in Construction Kulliyyah of Architecture and Environmental Design, International Islamic University Malaysia. 8 th May 2014

Abdul Rashid, K., Hasan, S.F. (2014b). Promoting Validity of the Istisna' For Construction Works Contracts Via the Bills of Quantities. 2nd World Conference on Islamic Thought \& Civilization

Abd Rashid, R., Mustapa, M., \& Abd Wahid, S. N. (2006). Bills of Quantities - Are They usefull and Relevant Today? In International Conference on Construction Industry (pp. 1-10).

Adnan, H., Mohd Nawawi, A. H., Mohd Akhir, S. M., Supardi, A., \& Chong, H. (2011). Bills of Quantities: Perspectives of Contractor in Malaysia. Australian Journal of Basic and Applied Sciences, 5(11), 863-873.

Bandi, S., \& Abdullah, F. (2012). Conceptualizing Issues relating to the Bills of Quantities. In ASEAN Post Graduate Seminar in the Built Environment. University Malaya. 
Baccarini, D., \& Davis, P. (2002). Bills of Quantities-A Literature Review. The Building Economist, 10-17.

Hansen, S., Salim, A. R. (2015). The Importance of Standard Method of Measurement in Indonesian Construction Industry. International Journal of Technology and Engineering Studies (IJTES), Vol. 1, no. 4, pp. 123-128.

Ganiyu, A.Y. \& Mohamed, S.F. 2012. Identification of the potentials and barriers of adopting standrad method of measurement for mechanical and electrical services in Malaysia. OIDA International Journal of Sustainable Development 3(1): 47-56.

Khalid, A.G., Omar, M.A., Peli, M. \& Utama, W.P. 2006. Peranan quantity surveyor di dalam industri konstruksi di Malaysia 1-4.

Krejcie, R.V., \& Morgan, D.W., (1970). Determining Sample Size for Research Activities. Educational and Psychological Measurement.

Mohammad, M. F. (2012). Standard Method of Measurement: A Review of Its Importance and Relevance in Quantity Surveying Practice. In International Seminar 2012 Responding to Global Challenges- The Need for Quantity Surveyor Professional Standard. Jakarta.

Muse, A. G., Sullivan, J. A., \& Smith, P. (2016). Improving Certainty In Construction: The Need For International Standards. ICEC XI World Congress.

Muzafar, S.A. (2021). Adoption Structural Modelling for Civil Engineering Standard Method of Measurement. Ongoing PhD Research. Unpublished Version.

Nizam Akbar, A. R., Mohammad, M. F., Ahmad, N., \& Mysham, M. (2014a). Adopting Standardization in Construction Environment: Standard Method of Measurement (SMMs). Procedia Social and Behavioral Sciences (Vol.17 0, pp 37-48).

Nizam Akbar, A. R., Mohammad, M. F., Ahmad, N., \& Mysham, M. (2014b). End Users Perception on the issues pertaining to the current Malaysian Standard Method of Measurement (SMMs). The Malaysian Surveyor, 49(2), 19-24.

Nizam Akbar, A. R., Mohammad, M. F., Talib, N. A., \& Mysham, M. (2014c). The Implication of the Standard Method of Measurement (SMMs) for Building Works toward Contractors' Works. In International Civil and Infrastructure Engineering Conference 2014 (InCIEC 2014). Kota Kinabalu, Sabah.

Nizam Akbar, A. R., Mohammad, M. F., Mysham, M., \& Hong, E. W. W. (2015). Desirable Characteristics of Malaysian Standard Method of Measurements (MySMMs) in Meeting Industry Quality Standards. Procedia - Social and Behavioral Sciences, (Vol.202, pp 76-88).

Nizam Akbar, A. R., Mohammad, M. F., Ahmad, N., \& Maisyam, M. (2018a). Standardization in Construction Environment: Adopting standard method of measurements. Asian Journal of Behavioural Studies, 3(12), 147-159. https://doi.org/10.21834/ajbes.v3i12.131

Nizam Akbar, A.R. (2018b). Framework in Remodelling New Malaysian Standard Method of Measurements (SMMs). Phd thesis, Universiti Teknologi MARA

Oluwatosin, T. \& Amos, O. 2016. Are quantity surveyors competent to value for civil engineering works? Evaluating QSs' competencies and militating factors Journal of Education and Practice 7(16): 9-18. www.iiste.org.

Perumal, V. R., \& Abu Bakar, A. H. (2011). The Needs for Standardization of Document Towards an Efficient Communication in the Construction Industry. ACTA Technica Corviniesis - Bulletin of Engineering, 1(January-March), 23-30. 